\title{
DRIVING SIMULATOR PERFORMANCE ACROSS THE LIFESPAN: A PRELIMINARY STUDY
}

Thomas D. Marcotte, Theodore Rosenthal, Erica Roberts, J. Cobb Scott, Rachel Meyer, and R. Wade Allen

University of California, San Diego

Systems Technology, Inc

E-mail: tmarcotte@ucsd.edu

\section{PAPER NOT AVAILABLE}

\begin{abstract}
\section{OBJECTIVES}

Normal aging is associated with decline in abilities that may put an individual at increased risk for a crash. Older individuals may have slowed processing speed and motor responses, a reduced useful field of view (Ball et al., 1988), and greater difficulty with mental rotation (Armstrong et al., 1998). Although collision rates increase with age (Transportation Research Board, 1988), it has been argued that specific age-related functional impairments, and not age itself, put one at risk (Ball \& Owsley, 2003). The goal of this study was to examine the relationship between aging and performance on driving simulations assessing specific components of drivingaccident avoidance, divided attention, and navigation - and the degree to which they predict onroad driving performance.
\end{abstract}

\section{METHODS}

Forty control drivers (age 22 to $84 ;<50$ yo, $\mathrm{n}=14 ; 50-70$ yo, $\mathrm{n}=13$; and $>70$ yo, $\mathrm{n}=13$ ) completed 3 simulations and an on-road driving evaluation. Exclusion criteria included neurologic confounds, substance use and psychiatric disorders, as well as abnormal neuropsychological performance (based upon demographically-corrected norms). The simulations were presented on a Pentium III PC computer using a 17' monitor at $1280 \times 1024$ resolution, and running STISIM Drive version 2.0 software (Systems Technology, Inc.; Hawthorne, CA). Hardware included a steering wheel, turn signal, and brake/accelerator pedals.

The simulations consisted of 1) Advanced Routine and Emergency Driving (ARED), a 15minute route simulating city/country driving, in which drivers must obey traffic signs, pass cars, and respond to high-risk crash scenarios; 2) Virtual City (VC), in which drivers must navigate to and from a location in a 5 x 5 block simulated city, and 3) Divided Attention, in which drivers are to maintain a constant speed and lane position while responding to divided attention tasks in the corner of the monitor. Participants also completed a 35-minute on-road assessment. Lastly, participants were assessed on a battery of neuropsychological tests. Earlier versions of the simulations were predictive of on-road driving performance in an HIV-infected cohort (Marcotte et al., 2004). 


\section{RESULTS}

The three groups performed similarly on ARED (crashes, speeding tickets), as well as on the VC task when the map was oriented to the same direction as the participant. On the other hand, older participants had significantly more difficulty navigating when their orientation on the map was reversed (e.g., the $<50$ group took 1.2 blocks beyond optimum to return from the destination; the $50-70$ and $>70$ years old groups took approximately 7.5 blocks). The three groups performed similarly with respect to lane deviation on the Divided Attention task, but the older groups had increased variability in speed maintenance, and the oldest group failed to respond to a greater number of divided attention stimuli $(<50$ yo $=.3(.83), 50-70$ yo $=1.0(1.3),>70$ yo $=3.6(2.7))$. Although only one participant failed the on-road drive (50-70 yo), the percent of drivers considered marginal or worse increased with age (7\% vs. $25 \%$ vs. $55 \%)$. In a logistic regression, the simulator variables that best discriminated safe vs. marginal on-road came from the Divided Attention task: the number of missed stimuli and speed deviation, both of which require an intact useful field of view and the shifting of gaze away from the roadway. Age did not enter into a model that included these variables.

\section{CONCLUSIONS}

In this study of normal, healthy controls, older participants drove similarly to young-to-middle aged participants on a simulation that most closely approximated real driving. Consistent with cognitive declines seen in normal aging, older participants had greater difficulty on a task requiring navigating when map orientation was reversed (perhaps indicative of impaired egocentric spatial abilities), as well as on a measure of driving-related divided attention, with older participants appearing to allocate more attention to the roadway at the cost of attending and responding to peripheral cues. Although older drivers had more difficulty during the on-road test, these difficulties were a function of deficits in the ability to divide attention efficiently, rather than aging per se.

\section{REFERENCES}

Armstrong, C.L., \& Cloud, B. (1998). The emergence of spatial rotation deficits in dementia and normal aging. Neuropsychology, 12(2), 208-217.

Ball, K.K., Beard, B.L., Roenker, D.L., Miller, R.L., \& Griggs, D.S. (1988). Age and visual search: Expanding the useful field of view. J Opt Soc Am A, 5(12), 2210-2219.

Ball, K., \& Owsley, C. (2003). Driving competence: It's not a matter of age. J Am Geriatr Soc, $51(10), 1499-1501$.

Marcotte, T.D., Wolfson, T., Rosenthal, T.J., Heaton, R.K., Gonzalez, R., Ellis, R.J., et al. (2004). A multimodal assessment of driving performance in HIV infection. Neurology, 63(8), 1417-1422.

Transportation Research Board. (1988). Transportation in an Aging Society, Vol 1. Washington, D.C.: National Research Council. 